LANGUAGE ACQUISITION, 14(3), 315-344

Copyright (๑) 2007, Lawrence Erlbaum Associates, Inc.

\title{
Morphosyntactic Learning and the Development of Tense
}

\author{
Julie Anne Legate \\ Cornell University \\ Charles Yang \\ University of Pennsylvania
}

\section{INTRODUCTION}

In this article, we propose that the Root Infinitive (RI) phenomenon in child language is best viewed and explained as the interaction between morphological learning and syntactic development. We make the following specific suggestions: The optionality in RI reflects the presence of a grammar such as Chinese which does not manifest tense marking. The gradual elimination of the nontense-marking grammar is facilitated by the learning of the morphosyntactic system of the target language. Quantitative differences in the input data among morphosyntactic systems result in the cross-linguistic variation in the RI phenomenon. More broadly, we aim to demonstrate that quantitative aspects of language learning data and concrete mechanisms of the language learning process can play an important role in the generative approach to language acquisition.

In Section 2, we give a brief overview of the RI literature along with some methodological remarks regarding the explanation of the phenomenon. In Section 3, we lay out our theory of morphosyntactic learning and the broader variational approach to language acquisition. Our empirical work focuses on the development of tense in Spanish, French, and English. In Section 4 we show through corpus study of child-directed speech that differences in the morphosyntactic systems of these three languages explain the brief RI stage in Spanish acquisition, the prolonged RI stage in English acquisition, as well the intermediate status of the RI stage in French. In Section 5, we discuss how our

Correspondence should be sent to Julie Anne Legate, Department of Linguistics, Cornell University, 217 Morrill Hall, Ithaca, NY 14853. E-mail: jal252@ cornell.edu 
approach relates to various findings established in the previous literature on RI. Section 6 concludes with a general discussion of the proper role of the input data in theories of language acquisition.

\section{PRELIMINARY REMARKS}

\subsection{The RI Phenomenon}

One needs no reminder that the problem of Root Infinitive (RI; also known as Optional Infinitive) occupies a central place in language acquisition research. Children learning a typologically diverse range of languages use nonfinite verbs in root clauses, which is not generally grammatical in the corresponding adult languages (Weverink (1989), Platzack (1990), Wexler (1994), Haegeman (1995), Harris and Wexler (1996), Bar-Shalom and Snyder (1997), Schaeffer and Ben Shalom (2004), among others). Some examples are given in (1):

(1) a. Papa have it.

b. thee drinken. tea drink-INF

c. Dormir petit bébé. sleep-INF little baby

d. mein Kakao hinstelln. my cocoa put-INF

e. Lashevel al ha-shulxan. sit-INF on the-table
(English)

(Dutch)

(French)

(German)

(Hebrew)

While in some of these languages, adults do use RI patterns in certain limited contexts (Rizzi (1994), Wijnen, Kempen, and Gillis (2001), Lasser (2002)), children's use of RI is more robust and is found in wider contexts than adults, indicating that a considerably different grammatical system is at play. ${ }^{1}$ The RI phenomenon, therefore, adds to the already impressive range of findings that language acquisition is not simply a matter of children replicating what they hear from adults.

It is important to bear in mind that the RI phenomenon is gradient, in two ways. First, there is no evidence that the exit from the RI stage is sudden: rather, the frequency of RI usage drops gradually to adult level, sometimes over the span of 2-3 years or even longer (Behrens (1993), Wijnen and Bol (1993), Haegeman (1995), Phillips (1995)). Second, and cross-linguistically, the distribution of the

\footnotetext{
${ }^{1}$ We note, however, that if adult use of root infinitives is significantly higher than zero, this could still be related to extended use of RI in children. We return to this point when we elaborate on our own proposal in Section 4: essentially, adult use of RI would be giving the child conflicting evidence about the obligatoriness of tense marking in her language.
} 
RI is not categorical but rather falls along a continuum. It appears that children learning most morphologically "rich" languages have shorter RI stages and lower frequency of use than those acquiring morphologically simpler languages (Phillips (1995), Wexler (1998), Guasti (2002)) — though as we shall see, the notion of "richness" is misleading and needs to be specified more precisely. For example, the production of RI ranges from rare in the Italian acquisition (Guasti (1992)), to a prolonged stage that may extend beyond the third birthday as in the case of Dutch (Haegeman (1995)) and English (Phillips (1995), Harris and Wexler (1996)).

\subsection{Approaches to RI}

Here we give a brief summary of some leading proposals in the RI literature. It is impossible in the current context to give a comprehensive survey of the existing theories on the RI phenomenon. Nor will we dwell on the virtues and problems with these proposals (see Phillips (1995), Wexler (1998), Guasti (2002), among others, for reviews). As will become evident later, our own proposal builds on the insights of many of the existing accounts.

One class of theories locates children's RI behavior in the core syntax, which is conjectured to be qualitatively different from that of an adult speaker of the target language. According to this view, an RI grammar may involve a tense node that is not interpreted at LF (Wexler (1994)), incomplete clausal structures (Rizzi (1994); cf. Radford (1990)), or different checking options in syntactic computation (Schütze and Wexler (1996), Wexler (1998)). Another class of theories relates RI to a combination of syntactic and nonsyntactic factors. For example, it is hypothesized that RI is due to underspecified features in the Tense node, which in turn are connected to the development of pragmatic knowledge (Hoekstra and Hyams (1998)), or to a phonologically null auxiliary that marks tense and represents related semantic properties (Boser, Lust, Santelmann, and Whitman (1992), Whitman (1994)). Still another group of theories links RI to nonsyntactic performance limitations. For instance, Avrutin (1999) suggests that RI results from children's limited resources to carry out utterance planning and other pragmatic computation, while Phillips (1995) attributes RI to the failure of merging the Tense node with the verb, resulting from not-yet-automatic use of morphological knowledge.

All these accounts have led to important empirical findings in the RI phenomenon, and have advanced our understanding of language acquisition and Universal Grammar in general. However, we believe that a number of crucial problems remain, some of which have not been frequently discussed.

In our opinion, a theory of RI, in addition to providing an insightful description of the RI stage, must also provide a specific model of how the child exits the RI stage (and why there should be an RI stage to begin with). In other words, what kind of learning mechanisms lead the child to abandon an RI grammar, 
and on the basis of what kind of learning data? Biological maturation, which presumably takes place largely independent of linguistic data, is one possibility (Rizzi (1994), Wexler $(1994 ; 1998)$ ). This proposal is not entirely satisfactory, however, as the mechanisms of biological maturation of linguistic ability are not currently well understood. Moreover, biological maturation abandons the Continuity Hypothesis (Macnamara (1982), Pinker (1984), Crain (1991), Carey (1995), de Villiers (2001)), the hypothesis that children's competence system is not qualitatively different from adults, which has served well in the investigation of child language and cognitive development.

More empirically, it is again useful to bear in the mind the gradient distribution of RI across languages as well as within languages. As noted earlier, the extent of RI use across languages varies quantitatively along a broad spectrum, and for languages with relatively long RI stages, the percentage of RI use declines gradually. Even during the RI stage, it is not the case that the child uses RI exclusively (hence the optionality of RI). These facts seem to indicate that the RI phenomenon cannot be a categorical or universal deficiency in children's grammar. Nor do they support the classic view of grammar development as an on-or-off process of switching parameter values, e.g., triggering (Gibson and Wexler (1994); see Yang (2002)). Finally, it seems unlikely that RI is entirely due to the limitations on processing and other performance sources. For example, there appears to be no independent reason to suppose that Italian children's pragmatic capacity is significantly more advanced than Dutch children's, whereas the former group has at most a very short RI stage and the latter group has a prolonged one. Given the strong correlation between the productivity of RI and the morphological richness of the language (Phillips (1995), Guasti (2002)), it appears that morphological learning must play a crucial—and quantitative-role in the explanation of the RI phenomenon.

Building on these insights from earlier work, we propose an alternative approach to the problem of Root Infinitives, one that is equipped with a concrete model of acquisition in which morphological learning across languages is connected to the underlying grammatical system of RI.

\section{OPTIONALITY, GRAMMAR, AND MORPHOLOGY}

\subsection{Variational Learning}

We assume the variational learning approach to language acquisition (Yang (1999; 2002; 2004); see Roeper (2000), Kroch (2001), Crain and Pietroski (2002), Rizzi (2005) for similar approaches). Under variational learning, the child's language is modeled as a population of hypotheses whose composition changes during the course of learning. In the present case, this population is an (innate) space of syntactic parameters specified by UG. Each grammar, or 
more specifically each parameter, is associated with a probability. It is this probability distribution that changes adaptively in response to the linguistic data in the environment. This differs critically from models such as triggering, where a unique grammar changes into another unique grammar on the basis of linguistic evidence.

Schematically, variational learning proceeds as follows:

(2) For an input sentence $s$, the child

a. with probability $P_{i}$ selects a grammar $G_{i}$,

b. analyzes $s$ with $G_{i}$

c. - if successful, reward $G_{i}$ by increasing $P_{i}$

- otherwise punish $G_{i}$ by decreasing $P_{i}$

A concrete instantiation, which models the well-known probability matching behavior in the psychology of learning (Bush and Mosteller (1951; 1958), Herrnstein and Loveland (1975); cf. Gallistel (1990)), is as follows:

(3) Given an input sentence $s$, the learner selects a grammar $G_{i}$ with probability $p_{i}$ :
a. if $G_{i} \rightarrow s$ then $\left\{\begin{array}{l}p_{i}^{\prime}=p_{i}+\gamma\left(1-p_{i}\right) \\ p_{j}^{\prime}=(1-\gamma) p_{j}\end{array} \quad\right.$ if $j \neq i$
b. if $G_{i} \not \supset s$ then $\left\{\begin{array}{l}p_{i}^{\prime}=(1-\gamma) p_{i} \\ p_{j}^{\prime}=\frac{\gamma}{N-1}+(1-\gamma) p_{j}\end{array} \quad\right.$ if $j \neq i$

In this model, known as Linear Reward Penalty, a parameter $\gamma$ controls the rate of learning, i.e., how much reward/punishment a grammar receives based on its success/failure in analyzing the input data on an item-by-item basis. We direct the reader to Yang (2002) for the formal properties of the variational model and in particular its application to a parametric space, while restricting ourselves to some general remarks here.

The basic learnability result is straightforward. Clearly, the target grammar, by being consistent with the input data, will never be directly punished. All other grammars in the UG space, however, are at least inconsistent with some portion of the input data. Thus, nontarget grammars will necessarily be driven to extinction by the target grammar, ensuring convergence. As a concrete example, consider the parameter of verb raising to tense. In the variational model, the learner initially has probabilistic access to both the + and the - value of the parameter. In a French-speaking environment, however, the - value will be punished. This is not to say that it will be punished all the time. For instance, a sentence such as "Jean voit Marie" obviously is consistent with both values 
of the parameter: in other words, the child learner will succeed regardless of whether she has selected the + or - value to analyze this sentence. When positional markers are present, however, as in the case of

(4) Jean voit souvent Marie. Jean sees often Marie. 'Jean often sees Marie.'

where the adverb follows the tensed verb, only the + value will succeed in analyzing the sentence. Hence, if the learner has probabilistically selected the + value for syntactic analysis, it will result in an increment of the probability associated with + . On the other hand, if the - value is selected, its failure in analyzing the sentence decreases its associated probability, and thus indirectly increasing that of the + value. It is clear that the + value, the target, will eventually eliminate the - competitor.

The probabilistic nature of the variational model has a number of features that distinguish it from the traditional conception of parameter setting. First, unlike the traditional models of learning such as triggering, even unambiguous evidence such as (4) does not settle learning decisively but only nudges the learner toward the target value. The rise of the target grammar is gradual, as its probability gradually approaches 1 ; this appears to be characteristic of language development in general. Second, the demise of nontarget grammars is also gradual. In other words, nontarget grammars may linger around for extended periods of time, albeit accessed with decreasing probabilities as they are gradually driven out by the target grammar. This leads to a principled interpretation of "errors" in child language as potential adult grammars sanctioned by UG, thus bringing the variational model in line with the guiding principle of the Continuity Hypothesis.

Finally, and more pertinent to the present article, the variational model makes it possible to integrate the theory of parameters into a quantitative model of language learning, as competing grammars may be associated with quantitative fitness values. A useful measure is the probability that a grammar is penalized in a specific linguistic environment, i.e., the percentage of sentences in the input that the grammar is inconsistent with. Adapting the formulation of Bush and Mosteller (1958), we have:

(5) The penalty probability of grammar $G_{i}$ in a linguistic environment $E$ is: $^{2}$

$$
c_{i}=\operatorname{Pr}\left(G_{i} \not \supset s \mid s \in E\right)
$$

\footnotetext{
${ }^{2}$ We write $s \in E$ to indicate that $s$ is an utterance in the environment $E$, and $G \rightarrow s$ to mean that $G$ can successfully analyze $s$. Formally, the success of $G \rightarrow s$ can be defined in any suitable way, possibly even including extra-grammatical factors; a narrow definition that we have been using is simply parsability.
} 
Ceteris paribus, the speed with which a grammar (or a parameter value) rises to dominance is correlated with its competitor's penalty probability. More formally, consider two grammars, target $G_{1}$ and the competitor $G_{2}$, with $c_{1}=0$ and $c_{2}>0$. At any time, $p_{1}+p_{2}=1$. With the presentation of each input sentence, the expected increase of $p_{1}, E\left[\Delta p_{1}\right]$, can be computed as follows:

$$
\text { (6) } \begin{array}{rlrl}
E\left[p_{1}\right]= & p_{1} \gamma\left(1-p_{1}\right) & \text { with Pr. } p_{1}, G_{1} \text { is chosen and } G_{1} \rightarrow s \\
& +p_{2}\left(1-c_{2}\right)(-\gamma) p_{1} & \text { with Pr. } p_{2}\left(1-c_{2}\right), G_{2} \text { is chosen and } \\
& & & G_{2} \rightarrow s \\
& +p_{2} c_{2} \gamma\left(1-p_{1}\right) & & \text { with Pr. } p_{2} c_{2}, G_{2} \text { is chosen but } G_{2} \not s s \\
= & c_{2} \gamma\left(1-p_{1}\right) & &
\end{array}
$$

that is, the increase of the probability of the target grammar $\left(p_{1}\right)$ is correlated with the penalty probability of the competitor $\left(c_{2}\right)$, which can be directly estimated from corpus studies of child directed speech. Note, however, that these fitness measures are not statistics that the child learner needs to explicitly keep track or make use of: this point has often been misunderstood (e.g., Westergaard (2006)). This, then, allows one to make quantitative comparisons for the development of different aspects of syntactic development (Legate and Yang (2002), Yang (2004)).

\subsection{Optionality as Probabilistic Grammar}

These unique features of the variational model suggest an alternative approach to the RI phenomenon. Previous theories, which include both generative accounts as well as empiricist learning accounts (e.g., Pine, Rowland, Lieven, and Theakston (2005)), have largely focused on the deviation of the RI grammar from the target grammar that the child eventually acquires. The variational framework, by contrast, seeks parallels between how the RI grammar deviates from the target grammar, and how the RI grammar relates to the totality of grammatical options made available by UG. It is therefore useful to turn to the typology of languages in search of possible competing grammars that may form the basis of optionality in the RI phenomenon. In all RI languages, tense is an active morphosyntactic feature of the grammar: call these [+Tense] languages. However, in many other languages - call these [-Tense] languages - tense is not expressed morphosyntactically. A few examples from Mandarin Chinese are given below. Although Mandarin Chinese lacks tense, the semantics of temporal distinctions may still be expressed in the language through adverbial adjuncts as in (7a) (see Enç (1987) and Smith (1991) for a discussion related to the semantic encoding of temporal relations in [-Tense] languages). Aspect morphology may also be present (7b): 
(7) a. Zhangsan tiantian da qiu. Zhangsan everyday play ball.

'Zhangsan plays ball everyday.'

b. Zhangsan zai da qiu.

Zhangsan ASP play ball.

'Zhangsan is playing ball.'

Important for the present discussion is that since UG makes [-Tense] grammars an available option (i.e., Mandarin Chinese is a human language), a child acquiring a $\left[+\right.$ Tense] language must rule out this option. ${ }^{3}$ Under the variational approach of probabilistic learning, the [-Tense] option may take nonzero time to be eliminated, and its elimination is based on the input data in the linguistic environment of $[+$ Tense] languages. If so, the use of nonfinite verbs in root clauses of [+Tense] languages is expected, and expected to be optional, as the [-Tense] option is accessed with a decreasing probability. ${ }^{4}$ When the $[-$ Tense] option is accessed, children will use verb forms that do not mark tense, i.e., infinitives. Thus, the differences between an RI-stage grammar and the full specification of UG are only quantitative, rather than qualitative, contrary to the biological maturation accounts.

\subsection{Morphological Evidence for Syntax}

On what basis does the child (gradually) eliminate the [-Tense] grammar in favor of the [+Tense] grammar? Most obviously, clauses with overt tense morphology, like English -ed, will reward the [+Tense] grammar and punish the [-Tense] grammar. However, the issue is more complex in two respects.

First, certain morphemes that do not express tense directly may nevertheless serve as evidence for the [+Tense] grammar. Consider English $-s$, which marks third singular, but only in the present tense. It is well established that children have determined the correct features realized by tense/agreement morphology well before they use them consistently; for example, Behrens (1993), Guasti (1992), Torres (1995) demonstrate that children's morphological errors are errors of omission, rather than use in inappropriate morphosyntactic contexts. In addition, there is evidence that English children can correctly identify English $3 \mathrm{Sg}-s$ as expressing $3 \mathrm{Sg}$ in the environment of present tense. For instance, Harris and Wexler (1996) show that even though English children do not use

\footnotetext{
${ }^{3}$ And thus we forgo a detailed discussion on the proper, but largely orthogonal, theoretical treatment of these languages, e.g., whether [-Tense] languages have identical clausal structure and functional nodes as [+Tense] languages.

${ }^{4}$ So far as we know, Weinberg (1994), in a commentary on Wexler (1994), was the only other researcher that suggested identifying the use of RI with a grammar like Chinese, although this proposal was not developed further by Weinberg.
} 
$-s$ consistently in third person singular present tense, they almost never use it in incorrect person/number combinations. Thus, tokens of $3 \mathrm{Sg}-s$, although not expressing tense, do require tense for their realization for what is known as secondary exponence in morphology. Therefore, these forms also reward the [+Tense] grammar and punish the [-Tense] grammar. When determining the frequency of relevant input to the child in any particular language, morphology that requires tense must be included (for related discussion, see Carstairs (1987) on primary versus secondary exponence, and Harley and Noyer (1999) on primary versus secondary expression of a feature).

Second, consider the impact of verb forms that are not overtly marked for tense, nor morphologically dependent on tense. In order for these forms to be compatible with a [+Tense] grammar, the learner must make the additional postulation of zero tense morphology. ${ }^{5}$ However, they are also compatible with a [-Tense] grammar: more straightforwardly so, in fact, for the [+Tense] option requires the postulation of zero morphology which may be disfavored for learnability reasons. If the child's language acquisition device attempts to analyze the form with a [-Tense] grammar, the analysis will be successful and the form will (ultimately incorrectly) punish the [+Tense] grammar, and reward the [-Tense] grammar. Eventually, the evidence for the [+Tense] grammar must overwhelm this apparent evidence for the [-Tense] grammar, and zero tense morphology will be consistently posited. However, until that point, the verb forms that exhibit no tense or tense-dependent morphology are liable to punish the target [+Tense] grammar. We should add that for languages in which adults do produce a nontrivial number of RIs (Rizzi (1994), Lasser (2002)) - Dutch, for example, (Wijnen et al. (2001)) - the rise of the [+Tense] option may be further delayed, for the child is bombarded with inconsistent data.

Note that in the present discussion, we have avoided the informal notion of a "rich" or "poor" morphology that has played a significant role in previous theories that have tried to address the cross-linguistic distribution of RI in acquisition. For us, the role of morphology in the rise of the [+Tense] grammar is a very specific one, i.e., that the tense feature is expressed, by either primary or secondary exponence. One can imagine a "poor" morphology devoid of number, gender, or person marking but with consistent tense marking; under our account, the [+Tense] grammar would rise to dominance quickly. Indeed, Japanese verbs do not have agreement morphology, ${ }^{6}$ but consistently mark Tense; notably, Japanese is not an RI language (Sano and Hyams (1994),

\footnotetext{
${ }^{5}$ The willingness to accept zero morphemes depends on one's theoretical persuasions; see, e.g., Anderson (1992) for a different view.

${ }^{6}$ Honorific markers have been considered a limited case of agreement (Harada (1976), Shibatani (1977), Boeckx and Niinuma (2004); see Bobaljik and Yatsushiro (2006) for an opposing view), but these do not appear on tensed verbs and thus would not provide evidence for a [+Tense] grammar.
} 
Sano (1999)). ${ }^{7}$ For us, then, it is important to quantify the amount of morphological evidence that could drive the learner along [ \pm Tense] one way or another: this needs to be done on a case-by-case basis, with a detailed analysis of the specific morphological system, and cannot be achieved by appealing to the informal notions "rich" and "poor." We turn to this question in Section 4.

\section{QUANTITATIVE EVIDENCE FOR TENSE ACROSS LANGUAGES}

Under our proposal, the evidence for the grammatical option of [ \pm Tense] is manifested in the verbal morphology of the language. Since the features active in the morphosyntax of a language are language-specific, they must be learned. Learning requires data, which in turn takes time to accumulate. On our view, this is where languages diverge with respect to RI: it is our contention that the morphological evidence for [+Tense] in languages with shorter RI stages is far more abundant than the morphological evidence in languages with extended RI use.

In this section, we quantify our claim with an analysis of the inflectional paradigms of three languages sampled from the RI spectrum — specifically, Spanish, French, and English - and situate the learning of the morphological systems of these languages in a broad context of morphosyntactic acquisition. It must be noted that the use of root infinitives, just like many other aspects of grammatical development, shows considerable individual variation. Thus, cross-linguistic generalizations of root infinitive use reflect tendencies rather than absolutes. And it is for this reason that we chose three languages for which children's quantitative uses of root infinitives are significantly different, and these differences have been consistently found in the research literature. Spanish is a language where children have relatively infrequent use of root infinitives. For example, Grinstead (1994) found that prior to 2;0, about $10 \%$ of otherwise finite verbs are infinitives, and by 2:6, this figure drops below 5\%. English, by contrast, has a much prolonged RI stage. As noted by Phillips (1995) (see also Hoekstra and Hyams (1998)), Adam's use of infinitives was still extensive at 3;0. Even the linguistically precocious Eve managed to produce approximately 50\% root infinitives by the time her recording sessions stopped at 2;3. In the acquisition of French, the frequency of root infinitives is found to be at 15-30\% for three children in the age group of approximately 1;8-2;6 (Rasetti (2003)), while Pierce's (1992) study of the same children reported somewhat higher frequencies.

\footnotetext{
${ }^{7}$ An interesting case would be a language that has rich agreement morphology yet little tense marking. Unfortunately, we are not aware of an empirical study on the acquisition of such a language.
} 
We show that the disparities across these three languages can be attributed to their verbal morphologies, which lead to the rapid decline of the [-Tense] grammar in Spanish, and a more gradual decrease in English, with French situated between these two extremes.

\subsection{Morphological Evidence for Tense in Spanish}

In order to estimate the amount of crucial data available to the Spanish child, we counted the frequency of tensed verb forms in child-directed Spanish. Of these forms, we counted how many express neither tense morphology, nor tensedependent morphology (see discussion of primary and secondary expression of features in Section 3.2 above), and thus are liable to incorrectly punish the [+Tense] grammar. Forms of the verb in Spanish that are overtly marked for tense and so were counted as correctly rewarding the $[+$ Tense $]$ grammar are the future, conditional, and imperfective.

(8) a. Future 3Sg cantar 'to sing' cantará

b. Conditional cantaría

c. Imperfective past cantaba

In contrast, the present tense of verbs in Spanish does not exhibit an overt tense morpheme; thus, any verbs in the present tense without tense-based agreement or other tense-based morphology would fall into this category of incorrectly punishing $[+$ Tense]. All person/number combinations, excepting the third singular discussed immediately below, exhibit agreement suffixes that do not appear on untensed verb forms-infinitivals and participles (the latter expressing aspect rather than tense). Therefore, these all correctly reward the [+Tense] grammar.

(9) a. Present cantar 'to sing'

$1 \mathrm{Sg}$ canto

$2 \mathrm{Sg}$ cantas

$3 \mathrm{Sg}$ canta

1Pl cantamos

2Pl cantáis

3Pl cantan

b. cf. Infinitive cantar

c. cf. Past Participle cantado

d. cf. Present Participle cantando 
The subjunctive uses the theme vowel $e$ throughout, which is not found on [-Tense] forms of $a r$ verbs, and thus was counted as rewarding the [+Tense] grammar.

(10) Subjunctive

$\begin{array}{ll}1 \mathrm{Sg} & \text { cante } \\ 2 \mathrm{Sg} & \text { cantes } \\ 3 \mathrm{Sg} & \text { cante } \\ 1 \mathrm{Pl} & \text { cantemos } \\ 2 \mathrm{Pl} & \text { cantéis } \\ 3 \mathrm{Pl} & \text { canten }\end{array}$

Finally, the perfective past exhibits tense-dependent morphology in all personnumber combinations, and so was counted as rewarding the [+Tense] grammar:

(11) Perfective past

$\begin{array}{ll}1 \mathrm{Sg} & \text { canté } \\ 2 \mathrm{Sg} & \text { cantaste } \\ 3 \mathrm{Sg} & \text { cantó } \\ 1 \mathrm{Pl} & \text { cantamos } \\ 2 \mathrm{Pl} & \text { cantasteis } \\ 3 \mathrm{Pl} & \text { cantaron }\end{array}$

Consider now the third singular form of the present: canta 'sings.' This form exhibits only the suffixal $a$ theme vowel of $a r$ verbs. Whether such forms reward or punish [+Tense] is dependent on the analysis of the theme vowel. ${ }^{8}$ Recent theoretical work on theme vowels in Spanish, Oltra-Massuet and Arregi (2005), argues that all theme vowels are dependent on tense (and agreement) in Spanish. Thus, third singular present forms will also reward [+Tense] in Spanish. This leads to an overwhelming preponderance of evidence for the [+Tense] grammar in Spanish, leaving only irregular imperatives that consist only of the bare stem, and any adult root infinitives, as potentially punishing [+Tense].

(12) Examples of bare stem imperatives

$\begin{array}{lll}\text { pon } & \text { poner } & \text { 'to put' } \\ \text { sal } & \text { salir } & \text { 'to leave' } \\ \text { ten } & \text { tener } & \text { 'to have' } \\ \text { ven } & \text { venir } & \text { 'to come' }\end{array}$

Although we find Oltra-Massuet and Arregi's work convincing, it is notable that the theme vowel for - $a r$ verbs $^{9}$ is $a$ in almost all of the [+Tense] forms of

\footnotetext{
${ }^{8} \mathrm{We}$ thank an anonymous reviewer for encouraging us to consider the issue of the theme vowel more closely.

${ }^{9}$ The highest theme vowel in Oltra-Massuet and Arregi's (2005) system.
} 
the - $a r$ verbs, including the third singular, and is $a$ in all three of the nonfinite forms. Thus we made the most conservative choice and counted the third singular present forms of -ar verbs as potentially punishing the [+Tense] grammar, while admitting that we may be underestimating the amount of evidence for the [+Tense] grammar available to the Spanish child. Regular imperative forms are identical to the third singular present and were treated identically.

(13) Imperative canta

The theme vowels for -er and -ir verbs do not exhibit the same consistency regardless of tense that is found in -ar verbs. Thus, we treated them as dependent on [+Tense], consistent with Oltra-Massuet and Arregi's analysis, and counted them as rewarding the [+Tense] grammar.

(14) a. Present vivir 'to live'

$1 \mathrm{Sg}$ vivo

$2 \mathrm{Sg}$ vives

$3 \mathrm{Sg}$ vive

$1 \mathrm{Pl}$ vivimos

2Pl vivís

$3 \mathrm{Pl}$ viven

b. cf. Infinitive vivir

c. cf. Past Participle vivido

d. cf. Present Participle viviendo

(15) a. Present comer 'to eat' $1 \mathrm{Sg}$ como

2Sg comes

3Sg come

1Pl comemos

2Pl coméis

3Pl comen

b. cf. Infinitive comer

c. cf. Past Participle comido

d. cf. Present Participle comiendo 
All other forms of -er and -ir verbs exhibit tense morphology or tense-based morphology and so reward the $[+$ Tense $]$ grammar.

(16) a. Future 3Sg vivir 'to live' vivirá

b. Conditional viviría

c. Imperfective past vivía

d. Imperative vive

(17) a. Subjunctive vivir 'to live' $1 \mathrm{Sg}$ viva

$2 \mathrm{Sg}$ vivas

$3 \mathrm{Sg}$ viva

1Pl vivamos

2Pl viváis

3Pl vivan

b. Perfective past

$1 \mathrm{Sg}$ viví

$2 \mathrm{Sg}$ viviste

3Sg vivió

$1 \mathrm{Pl}$ vivimos

2Pl vivisteis

3Pl vivieron

(18) a. Future $3 \mathrm{Sg}$ comer 'to eat' comerá

b. Conditional comería

c. Imperfective past comía

d. Imperative come

(19) a. Subjunctive comer 'to eat' $1 \mathrm{Sg}$ coma

2Sg comas

$3 \mathrm{Sg}$ coma

1Pl comamos

2P1 comáis

3Pl coman 
b. Perfective past

$\begin{array}{ll}1 \mathrm{Sg} & \text { comí } \\ 2 \mathrm{Sg} & \text { comiste } \\ 3 \mathrm{Sg} & \text { comió } \\ 1 \mathrm{Pl} & \text { comimos } \\ 2 \mathrm{Pl} & \text { comisteis } \\ 3 \mathrm{Pl} & \text { comieron }\end{array}$

Finally, several classes of Spanish verbs require a stem change in the singular and in the third plural of the present tense. ${ }^{10}$ An example follows:

(20) a. Stem change in present tense: poder 'be able to'

$1 \mathrm{Sg}$ puedo

$2 \mathrm{Sg}$ puedes

3Sg puede

1Pl podemos

2Pl podéis

3Pl pueden

b. cf. Infinitive poder

c. cf. Past Participle podido

d. cf. Present Participle podiendo

e. Imperative puede

This stem change again requires tense for its application, and thus correctly rewards the $[+$ Tense] grammar. The third singular present and second singular imperative forms of such verbs thus were not counted as punishing the [+Tense] grammar.

These counting criteria for Spanish are summarized in Table 1. We examined the child-directed utterances from 14 files in the Fernández and Aguado corpus in the CHILDES database (MacWhinney (1995)). The counts were carried out by hand. Table 2 reports our findings.

There are $1782 / 2226=80.1 \%$ of input tensed verbs with verbal morphology that unambiguously implicate the [+Tense] grammar. These are countered by only $444 / 2226=19.9 \%$ of input tensed verbs that, by virtue of being consistent with the [-Tense] grammar, may impede the gradual dominance of the [+Tense] grammar. The [+Tense] grammar has a significant numerical advantage: $60.2 \%$.

\footnotetext{
${ }^{10}$ This stem change is also found in the present subjunctive and the imperative, both of which arguably involve (present) tense.
} 
TABLE 1

Types of Morphological Evidence in Spanish for Acquisition of [ \pm Tense]

\begin{tabular}{|c|c|c|}
\hline & Rewards [-Tense] Grammar & Rewards [+Tense] Grammar \\
\hline \multirow[t]{3}{*}{-ar } & $3 \mathrm{Sg}$ present & All other present tense forms \\
\hline & Imperative & Future, conditional, imperfective past \\
\hline & & Perfective past, subjunctive \\
\hline \multirow[t]{2}{*}{-ir, -er } & & Present \\
\hline & & Imperative, future, conditional, imperative past \\
\hline Irregular & & Stem change \\
\hline \multirow[t]{2}{*}{ Irregular } & $2 \mathrm{Sg}$ bare stem imperatives & \\
\hline & Adult use of root nonfinite verbs & \\
\hline
\end{tabular}

The morphology of Spanish, then, offers the child ample opportunity to learn that their language makes use of tense.

If our approach to RI is on the right track, then the cross-linguistic distribution of RI is due to the (gradient) quantities in the morphological evidence for the [+Tense] grammar. We would therefore expect that the extended RI languages have a smaller amount of evidence for the marking of Tense than a brief RI language such as Spanish. To this end, we turn to a corpus study of childdirected English.

\subsection{Morphological Evidence for Tense in English}

In order to estimate the amount of crucial data available to the English child, we counted the frequency of verb forms that express tense, or require tense for their usage, that are present in adult speech in English CHILDES. (Again, see the previous discussion of primary and secondary expression of features.)

In English, past tense is overtly marked for most regular and irregular verbs, for example, jump-ed and burn-t; all such tokens were counted as evidence for [+Tense]. In addition, a class of irregular verbs with no tense suffix exhibit stem allomorphy dependent on the past tense, for example, sang. These were counted as well. In the present, third person singular shows the tense-dependent

TABLE 2

Quantitative Evidence of Verbal

Inflection in Child-Directed Spanish for Acquisition of [ \pm Tense]

\begin{tabular}{lc} 
Rewards [+Tense] & $1782 / 2226$ \\
Rewards [-Tense] & $444 / 2226$ \\
([+Tense]-[-Tense])\% & $60.2 \%$ \\
\hline
\end{tabular}


TABLE 3

Types of Morphological Evidence in English for Acquisition of [ \pm Tense]

\begin{tabular}{lll}
\hline & Rewards [-Tense] Grammar & Rewards [+Tense] Grammar \\
\hline Past tense & No change irregulars & All the rest \\
Present tense modal & All & \\
Present tense verbs & All the rest & Third person singular \\
Present tense auxiliary & & All \\
Bare stem verbs & All & \\
\hline
\end{tabular}

$-s$; such tokens reward the [+Tense] grammar. In addition, the auxiliary be in the present tense (i.e., am, are, is), including the contracted forms (which are abundant in child-directed speech), shows agreement in the present tense, and therefore counts as secondary exponence evidence for the [+Tense] grammar.

On the other side of grammar learning, forms in English exhibiting zero expression of tense and no tense-dependent morphology were counted as potential evidence against the [+Tense] grammar. In English these include, obviously, the non-third singular forms of regular verbs in the present tense. Likewise, modals in the present tense, which do not mark for agreement at all, are included as well. In addition, utterances that contain only a bare verb such as "play checkers?" and "leave them in there," which are indistinguishable from a Chinese-like [-Tense] grammar, are also included. Finally, a small class of verbs that do not change in past tense, for example, hit-hit, also punish the [+Tense] grammar; these verbs are tallied as well. All the verbal forms that we have counted are summarized in Table 3. We took a random sample of 58,447 child-directed sentences from Brown's (1973) Harvard studies. Because English morphology is relatively simple, and the distributional cues for morphological analysis are relatively clear, there are industrial strength, part-of-speech tagging tools that are sufficiently accurate and informative, thereby making large-scale corpus analysis possible. For the present study, we used the part-of-speech tagger of Brill (1995), which achieves an accuracy of 95-97\% on unrestricted English texts: this level of performance is acceptable for our purposes. ${ }^{11}$ The results of our counts are summarized in Table 4. The input analysis of English morphology reveals that there is in fact relatively little unambiguous evidence for the [+Tense] option in the grammar. Though [+Tense] still possesses the numerical advantage-a net difference of $5.8 \%$ - it is far less robust than in the case of Spanish (60.2\%).

\footnotetext{
${ }^{11}$ For instance, the tagger can correctly distinguish infinitives ('to run') from nonthird person singular present tense ('I run'). We have noted, however, that for technical reasons that needn't concern us here, the tagger often mis-tags words immediately preceding the contracted negation marker ("n't"). These were manually corrected.
} 
TABLE 4

Quantitative Evidence of Verbal Inflection in Child-Directed English for [ \pm Tense] Acquisition

\begin{tabular}{lc}
\hline Rewards [+Tense] & $37090 / 70047$ \\
Rewards [-Tense] & $32857 / 70047$ \\
([+Tense]-[-Tense])\% & $(52.9-47.1)=5.8 \%$ \\
\hline
\end{tabular}

\subsection{Morphological Evidence for Tense in French}

Finally, we considered the evidence available to the French child regarding the status of the [+Tense] grammar in her language. The future and conditional show overt tense marking and so correctly reward the [+Tense] grammar. The imperfective past also correctly rewards the [+Tense] grammar through tensedependent agreement morphology:

(21) a. Future $3 \mathrm{Sg}$ chanter 'to sing' chantera

b. Conditional chanterait

c. Imperfective past chantait

Similarly to Spanish, French does not exhibit overt tense marking in the present or the imperative. The agreement morphology found in French is significantly more impoverished as compared to Spanish. An -er verb paradigm follows; in contrast to Spanish, the only pronounced suffixes are those in the first plural and second plural; other forms are pronounced as bare stems. The second plural suffix is identical to the infinitive and past participle, leaving the first plural as the only tense-dependent agreement morphology.

(22) a. Present chanter 'to sing'

$1 \mathrm{Sg}$ chante

$2 \mathrm{Sg}$ chantes

$3 \mathrm{Sg}$ chante

1Pl chantons

2P1 chantez

3Pl chantent

b. cf. Infinitive chanter

c. cf. Past Participle chanté 
d. cf. Present Participle chantant

e. Imperative chante

In the -re verb paradigm, the first and second plural exhibit tense-dependent morphology.

(23) a. Present vendre 'to sell'

$1 \mathrm{Sg}$ vends

$2 \mathrm{Sg}$ vends

$3 \mathrm{Sg}$ vend

1Pl vendons

2Pl vendez

3Pl vendent

b. cf. Infinitive vendre

c. cf. Past Participle

vendu

d. cf. Present Participle vendant

e. Imperative vends

In the -ir verb paradigm, all singular present forms exhibit only the /i/ suffix found on the past participle. The third plural form exhibits only the /is/ suffix found in the present participle. Thus, again only first and second person plural exhibit tense-based agreement morphology. ${ }^{12}$

(24) a. Present grandir 'to grow'

$1 \mathrm{Sg}$ grandis

$2 \mathrm{Sg}$ grandis

$3 \mathrm{Sg}$ grandit

1Pl grandissons

2Pl grandissez

3Pl grandissent

b. cf. Infinitive grandir

\footnotetext{
${ }^{12} \mathrm{The} / \mathrm{i} / \mathrm{suffix}$ may be comparable to the Spanish /a/ theme vowel, both found in most [ + Tense] and all [-Tense] forms of the verb.
} 

c. cf. Past Participle grandi
d. cf. Present Participle grandissant
e. Imperative grandis

Thus, more present verb forms in French than in Spanish fail to provide unambiguous evidence for the [+Tense] grammar. This is all the more true in that the first plural and second plural are infrequently used in spoken French: such forms were rare, but present, in our data.

Like Spanish, many French verb forms exhibit tense-based stem change in the present. These, despite the lack of overt agreement or tense morphology, do provide evidence for the [+Tense] grammar. An example follows.

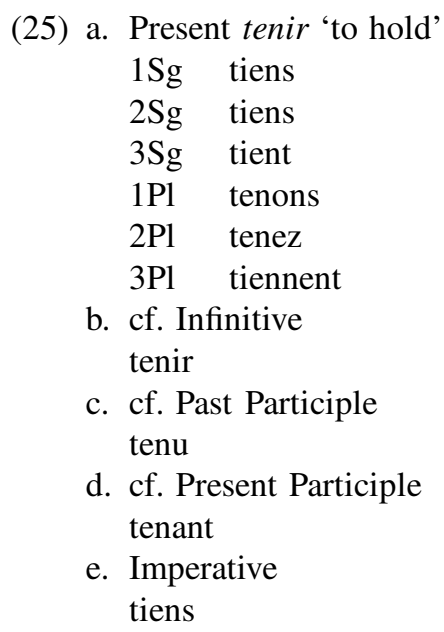

Such verbs found in the selection included tenir, re(venir), savoir, pouvoir, vouloir, falloir, devoir, sortir. In addition, the verbs aller, avoir, and être (excepting the second plural) show significant stem allomorphy in the present, and thus also provide evidence for the [+Tense] grammar:

(26) a. Present aller 'to go'

$\begin{array}{ll}1 \mathrm{Sg} & \text { vais } \\ 2 \mathrm{Sg} & \text { vas } \\ 3 \mathrm{Sg} & \text { va } \\ 1 \mathrm{Pl} & \text { allons } \\ 2 \mathrm{Pl} & \text { allez } \\ 3 \mathrm{Pl} & \text { vont }\end{array}$


b. Present être 'to be'

$1 \mathrm{Sg}$ suis

$2 \mathrm{Sg}$ es

$3 \mathrm{Sg}$ est

1Pl sommes

2Pl êtes

3Pl sont

c. Present avoir 'to have'

$\begin{array}{ll}1 \mathrm{Sg} & \text { ai } \\ 2 \mathrm{Sg} & \text { as } \\ 3 \mathrm{Sg} & \text { a } \\ 1 \mathrm{Pl} & \text { avons } \\ 2 \mathrm{Pl} & \text { avez } \\ 3 \mathrm{Pl} & \text { ont }\end{array}$

This counting procedure for French is summarized in Table 5.

We examined child-directed utterances from the Leveille corpus (Philippe) and the Geneva corpus (Marie) in the CHILDES database. The counts were carried out by hand. Table 6 reports our findings. There are 1558/2231 $=69.8 \%$ of input tensed verbs with verbal morphology that unambiguously implicate the [+Tense] grammar. These are countered by $673 / 2231=30.2 \%$ of input tensed verbs that, by virtue of being consistent with the [-Tense] grammar, may impede the gradual dominance of the $[+$ Tense] grammar. The numerical advantage of the [+Tense] grammar in French is thus 39.6\%. The morphology of French, then, provides far more opportunity for the child to learn that the tense is an active morphosyntactic feature in their language than English, but not as much as Spanish. The status of the French RI stage as intermediate between English and Spanish, but closer to Spanish, is thus directly explained by our model. The results from the corpus study are summarized in Table 7.

TABLE 5

Types of Morphological Evidence in French for Acquisition of [ \pm Tense]

\begin{tabular}{lll}
\hline & \multicolumn{1}{c}{ Rewards [-Tense] Grammar } & \multicolumn{1}{c}{ Rewards [+Tense] Grammar } \\
\hline -er & All other present forms & 1Pl present \\
& & Future, conditional, imperfective past \\
& & Subjunctive, imperative \\
-re, -ir & All other present forms & $1 \mathrm{Pl}$ present, 2Pl present \\
& & Future, conditional, imperfective past \\
& & Subjunctive, imperative \\
Irregular & Adult use of root nonfinite verbs & \\
& & \\
\hline
\end{tabular}


TABLE 6

Quantitative Evidence of Verbal Inflection in Child-Directed French for Acquisition of [ \pm Tense]

\begin{tabular}{lc}
\hline Rewards [+Tense] & $1558 / 2231$ \\
Rewards [-Tense] & $673 / 2231$ \\
([+Tense]-[-Tense])\% & $39.6 \%$ \\
\hline
\end{tabular}

\section{MORPHOLOGY LEARNING AND SYNTACTIC DEVELOPMENT}

Our proposal in this article constitutes a learning-theoretic model that retains many insights of the previous analyses of the RI phenomenon. We agree with all (generative) accounts that RI is a genuine grammatical phenomenon rooted in UG and by virtue of its derivation from the target grammar along with the associated grammatical properties, constitutes a forceful argument against the empiricist position to language acquisition. We agree with Schütze and Wexler (1996) and Wexler (1998) that there is a connection between tense and agreement marking in both child and adult grammars, and in particular, that tense and agreement may be separately licensed. We agree with Hoekstra and Hyams (1998) and Schaeffer and Ben Shalom (2004) in recognizing that morphology plays an important and revealing role in the underlying grammatical system of Tense. In addition, for Boser et al. (1992) and Whitman (1994), RI results from a null auxiliary whose function is, among others, to spell out the tense feature; for us, it results from the presence of a [-Tense] grammar, which eliminates the need to spell out the tense feature.

Perhaps our account is closest to that of Phillips (1995), which also relates morphological learning to RI in a quantitative way. In Phillips' account, the underlying grammar system during the RI stage is much like the target adult grammar and the performance of the child's morphological system-specifically,

TABLE 7

Quantitative Comparisons of the Amount of Morphological Evidence in Favor of the [+Tense] Grammar and the Reported Duration of the RI Stage in Three Languages

\begin{tabular}{lcc}
\hline Language & \% for $[+T]-\%$ for $[-T]$ & Duration of RI \\
\hline Spanish & $60.2 \%$ & $\sim 2 ; 0$ \\
French & $39.6 \%$ & $\sim 2 ; 8$ \\
English & $5.8 \%$ & $>3 ; 5$ \\
\hline
\end{tabular}


the realization of inflectional features-is directly responsible for the use of RI. In our account, the underlying RI grammar system is a statistical ensemble of potential adult-like grammars (including but not limited to the target grammar), and that is because the morphological system, whose development is frequency sensitive, has not yet driven out the [-Tense] option.

By providing a unified framework in which the interaction of morphology and grammar learning can be addressed, our model complements previous models in the RI literature. Space prohibits us from providing a thorough survey; below we discuss two results that have received considerable attention in the literature.

Upon close scrutiny, not all findings reported in the literature can be maintained. For instance, an oft-cited generalization concerns the clustering of null subjects and nonfinite verbs on the one hand, and that of overt subjects and finite verbs on the other. Unfortunately, this generalization does not hold up cross-linguistically, as noted by Phillips (1995), among others. In addition, there are distributional generalizations in children's null subjects that pattern with a topic-drop grammar rather than the tense of the verb (Yang (2002)). Finally, the developmental time courses of null subjects and RI simply do not match. For instance, Figure 1 reproduces the longitudinal developments of null subjects and RI of a Dutch child (the Hein corpus; Haegeman (1995)): Note that his RI stage essentially ended at 3;0-3;1, when his usage dropped to around 5\%, yet there were still about $30 \%$ of null subject sentences in his production.

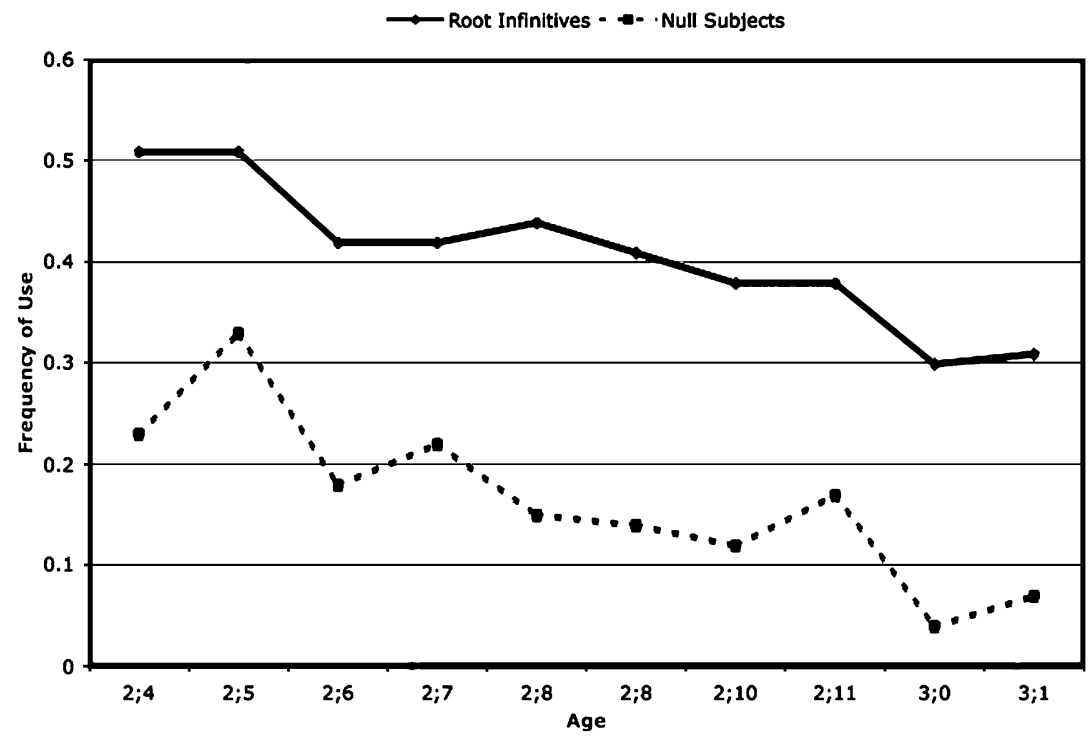

FIGURE 1 The longitudinal development of null subjects and RI; data from Haegeman (1995). 
Consider next, another prominent finding in the RI research, which concerns the relation between the form of verbs and the syntactic positions they occupy. Since Weverink (1989) and Pierce (1992), it has been known and since robustly confirmed (see Wexler (1994) for a summary) that verbs raising to a high position (e.g., T) in the matrix clause-as indicated by positional markers such as negation or adverb-are almost always finite, whereas the verbs that remain in-situ-also indicated by negation and adverb-are almost always nonfinite. And this is apparently so even for children barely in the multi-word stage of syntactic acquisition. The following findings from Deprez and Pierce (1993) are typical:

(27) a. marche pas works not

b. elle a pas she has not the mouth

c. pas la poupée dormir not the doll sleep

d. pas chercher les voitures not look.for the cars (finite \& high)

(finite \& high)

(nonfinite \& low)

(nonfinite \& low)

Under our framework, a straightforward way to account for this pattern is to assume that, as a matter of UG principle, [+Tense] grammar is a necessarythough not sufficient-condition for raising the verb. This can be viewed as building on the insight of Pollock (1989) through (early) minimalism that one of the means of spelling out the Tense features-in, by definition, a [+Tense] grammar-is to move the verb to $\mathrm{T}$, whereas another option is to lower $\mathrm{T}$ to the verb, as in the case of English. Though we are not aware of any counterexample to this position, it would nevertheless commit us to the position that verbs do not undergo movement to Tense or similar functional nodes in [-Tense] grammars such as Chinese-which at least one of us is not comfortable with.

Another way of accounting for the data in (27) more closely follows the spirit of probabilistic and quantitative learning advanced in the present article. The observed fact means that children at a fairly young age have learned, as a fact about their specific languages, that Tense is far more likely to be inflected when the verb is high — as indicated by its position relative to negative and VP-level adverbs - than otherwise, and indeed, they very quickly learn that the probability of the former is close to 1 . This notion can be captured in terms of conditional probabilities:

(28) $\mathrm{P}([+$ Tense $] /$ Verb high $) \approx 1 \gg \mathrm{P}([+$ Tense $])$.

Thus, we again quantitatively measured the amount of evidence that is used to learn these probabilities. Here we considered the child-directed speech in the 
TABLE 8

Verb Form and Position in Child-Directed French

\begin{tabular}{lcc}
\hline Verb Position & Rewards [+Tense] & Rewards [-Tense] \\
\hline High & $138(90.2 \%)$ & $15(9.8 \%)$ \\
Ambiguous & $687(66.8 \%)$ & $342(33.2 \%)$ \\
\hline
\end{tabular}

files of one of the two French children examined in Section 4.3, as the statistical evidence for tense for them is virtually the same. To this end, we have separated verbs into two classes, focusing specifically on those that are unambiguously high. For those, we expect the evidence for the [+Tense] option is far more abundant than verbs that are not unambiguously high. To gather these statistics, we consider two cases for which the verb is unambiguously high:

(29) a. verbs that precede negation or adverb, such as (4)

b. verbs that precede the subject, such as the phrase commonly used to introduce a question in French est-ce que ('is it that'), where the verb has raised to $\mathrm{C}$-and thus at least to $\mathrm{T} .{ }^{13}$

Of course, verbs that are unambiguously high may be morphologically ambiguous for the $[ \pm$ Tense] option. After all, some verbs have null tense morphemes that render them indistinguishable from nonfinite ones; see the discussion of the French verbal paradigm and its relation to tense marking in Section 4.3. However, the numerical advantage of unambiguously [+Tense] verbs in high positions is compelling (thanks largely to morphologically finite auxiliaries). Our results are summarized in Table 8.

Indeed, when the verb is high, it overwhelmingly rewards the [+Tense] grammar. The advantage for [+Tense] when conditioned upon a high verb position is almost $80 \%$, which is even considerably higher than that in Spanish $(60.1 \%$; see Section 4.1). Given the fact that the Spanish RI stage is very short if existent at all, we have every reason to expect that the [+Tense] option can be determined reliably by French children when the verb is in high clausal positions. ${ }^{14}$

\footnotetext{
${ }^{13}$ It has been argued that some post-verbal subjects in child French are VP-internal (Deprez and Pierce (1993)), but this position has been convincingly disconfirmed with much larger corpus work (Stromswold and Zimmerman (1999)): the subject consistently moves out of the VP and is presumably located in the Spec of T. Thus, any verb that precedes the subject can be taken as evidence that it has raised to a higher position.

${ }^{14}$ In child-directed French, we expect all verbs that are unambiguously low are nonfinite; otherwise, the utterance would be ungrammatical. Thus, $\mathrm{P}([-$ Tense $]$ IVerb low $)$ must approach 1 rapidly for the evidence would be completely one-sided. This, of course, accounts for the other side of the findings in (27) that low verbs are almost always nonfinite.
} 


\section{LEARNING AND UNIVERSAL GRAMMAR}

The use of probabilistic learning in the variational model is connected to, and in fact draws insights from, learning problems in other cognitive and perceptual domains (Bush and Mosteller (1958), Herrnstein and Loveland (1975)). However, it is worth stressing that this in no way denies or replaces the critical assumption of UG. After all, the selection of grammars in learning requires a pool of candidates to select from, and that is supplied by parameters and UG (see Yang (2002; 2004) for additional discussions). Indeed, an interesting direction for research may focus on the properties of root infinitives and their interactions with the development of the aspect system; see Wijnen (1997), Becker (2000), Hyams (2007/this issue) among others, for an extensive investigation, where it has been observed that most RI usage in child language expresses temporal and modal meanings. For example, Hyams (2007/this issue) argues that RIs in a typologically diverse range of languages are interpreted by the aspectual properties of the predicate. When integrated with our approach to RI, it means that a possible grammar in UG may use either Tense or Aspect to encode temporal meanings - sometimes both, but never neither. If so, then the [-Tense] grammar, when accessed, necessarily has an aspectual interpretation, consistent with the observations in the literature (Austin (2002)). This would further reveal the role of domain-specific linguistic knowledge in language acquisition even if the learning mechanism is domain-general. We leave the exploration of this connection with previous work for future research.

The variational model does raise the possibility that the mechanisms of language acquisition may be part of what Hauser, Chomsky, and Fitch (2002) call the Faculty of Language in the Broad sense (FLB). One direction in which this view can be empirically pursued concerns individual variations in language acquisition. More directly, the model of morphosyntactic learning advocated here may offer an explanation for the extended RI stage in a population of SLI children (Rice and Wexler (1996), Rice, Wexler, and Hershberger (1998)). For us, the extended RI stage is not the result of underlying grammatical deficits. Rather, as has been well documented in the acquisition of past tense (Leonard et al. (1992), Rice, Wexler, Marquis, and Hershberger (2000), and the references cited therein), SLI children may simply be slow morphological learners, which in turns slows down the emergence of the [+Tense] grammar under the current proposal that the frequency-sensitive mastery of language-specific morphology plays a crucial role in the course of grammar elimination. Also of relevance is a group of SLI learners who exercise nontarget but UG-compatible options of grammar (van der Lely and Battell (2003)), precisely replicating the pattern of acquisition in normal developing children (McDaniel (1989), Thornton (1990)). Thus it seems that this specific SLI population are simply slower learnerswhich can be formally characterized in the variational learning framework by a parameter of learning rate that dictates the amount of punishment/reward in 
grammar competition-rather than learners with specific deficits in the core grammatical system. ${ }^{15}$ In a theory where the roles of morphological learning and syntactic acquisition are clearly articulated, it may be possible to identify more precisely the source of language learning deficits in the notoriously heterogeneous symptoms of SLI children.

In conclusion, we would like to suggest that both the input data and the mechanisms by which children internalize grammar on the basis of the input data be taken seriously in the generative approach to language acquisition. Doing so in no way diminishes the importance of Universal Grammar, but Universal Grammar does not have to do all the work in order for language acquisition to succeed. Under the contemporary idea that much of language variation (and thus acquisition) comes down to the acquisition of the lexicon, it would seem more pressing to develop a theory of experience-dependent language learning. (If anything is learned, it's words.) For aspects of the grammar that take time to complete (such as the RI phenomenon), it remains a possibility that the child is not receiving a sufficient amount of relevant linguistic evidence: what "counts" as relevant linguistic evidence will inevitably turn to UG, for the child does not simply match and replicate what is presented in the input. It might be added that even for aspects of grammars that children can successfully acquire very rapidly, it is also desirable to have a specific account of the learning mechanism, and how that mechanism makes use of the input data so spectacularly. UG is a biological miracle, but learning needn't be.

\section{ACKNOWLEDGMENTS}

We would like to thank the audiences at Yale University, University of Pennsylvania, and Université de Genève where portions of this article have been presented. We are especially grateful to Misha Becker and three anonymous reviewers for the journal for very helpful suggestions and criticisms, which significantly improved the article. Finally, we would like to acknowledge the work of Alison Austin (2002), and the many discussions with her that led to that work and paved the path to this.

\section{REFERENCES}

Anderson, S. (1992) A-Morphous Morphology. Cambridge University Press, Cambridge.

Austin, A. (2002) Tense or Aspect: What Auxiliaries Can Tell Us About Optional Infinitives, Senior essay in Cognitive Science, Yale University, New Haven, CT.

Avrutin, S. (1999) Development of the Syntax-Discourse Interface, Kluwer, Dordrecht.

\footnotetext{
${ }^{15}$ See also Franks and Connell (1996); we thank Steve Franks for pointing out the relevance of their work.
} 
Bar-Shalom, E. and W. Snyder (1997), "Root Infinitives in Child Russian: A Comparison with Italian and Polish," in A. Sorace, C. Heycock, and R. Shillcock, eds., Proceedings of the GALA 1997 Conference on Language Acquisition, University of Edinburgh, Edinburgh.

Becker, M. (2000) The Development of the Copula in Child English: The Lightness of Be. Doctoral dissertation, University of California, Los Angeles.

Behrens, H. (1993) Temporal Reference in German Child Language, Doctoral dissertation, University of Amsterdam.

Bobaljik, J. D. and K. Yatsushiro (2006) "Problems with Honorification-as-Agreement in Japanese: A Reply to Boeckx and Niinuma," Natural Language and Linguistic Theory 24, 355-384.

Boeckx, C. and F. Niinuma (2004) "Conditions on Agreement in Japanese," Natural Language and Linguistic Theory 22, 453-480.

Boser, K., B. Lust, L. Santelmann, and J. Whitman (1992) "The Syntax of CP and V2 in Early Child German: The Strong Continuity Hypothesis," in K. Broderick, ed., Proceedings of the North East Linguistic Society 23, Amherst, MA.

Brill, E. (1995) "Transformation-Based Error-Driven Learning and Natural Language Processing: A Case Study in Part of Speech Tagging," Computational Linguistics 21, 543-565.

Brown, R. (1973) A First Language: Early Stages, Harvard University Press, Cambridge, MA.

Bush, R. and F. Mosteller (1951) "A Mathematical Model for Simple Learning," Psychological Review, 68, 313-323.

Bush, R. and F. Mosteller (1958) Stochastic Models for Learning, Wiley, New York, NY.

Carey, S. (1995) "Continuity and Discontinuity in Cognitive Development," in D. Osherson, ed., An Invitation to Cognitive Science, Vol. 3, MIT Press, Cambridge, MA.

Carstairs, A. (1987) Allomorphy in Inflection, Croom Helm, London.

Crain, S. (1991) "Language Acquisition in the Absence of Experience," Behavioral and Brain Sciences 14, 597-650.

Crain, S. and P. Pietroski (2002) "Why Language Acquisition is a Snap," Linguistic Review 19, $163-183$.

Deprez, V. and A. Pierce (1993) "Negation and Functional Projections in Early Grammar," Linguistic Inquiry 24, 25-67.

Enç, M. (1987) “Anchoring Conditions for Tense," Linguistic Inquiry 18, 633-657.

Franks, S. and P. Connell (1996) "Knowledge of Binding in Normal and SLI Children," Journal of Child Language 23, 431-464.

Gallistel, R. (1990) The Organization of Learning, MIT Press, Cambridge, MA.

Gibson, E. and K. Wexler (1994) "Triggers," Linguistic Inquiry 25, 355-407.

Grinstead, J. (1994) Consequences of the Maturation of Number Morphology in Spanish and Catalan, M.A. thesis, University of California, Los Angeles.

Guasti, M. T. (1992) "Verb Syntax in Italian Child Grammar," Geneva Generative Papers 1, 115122.

Guasti, M. (2002) Language Development: The Growth of Grammar, MIT Press, Cambridge, MA.

Haegeman, L. (1995) "Root Infinitives, Tense, and Truncated Structures," Language Acquisition 4, $205-255$.

Harada, S.-I. (1976) "Honorifics," in M. Shibatani, ed., Syntax and Semantics 5, Academic Press, New York.

Harley, H. and R. Noyer (1999) "Distributed Morphology," Glot International 4, 3-9.

Harris, T. and K. Wexler (1996) "The Optional-Infinitive Stage in Child English," in H. Clahsen, ed., Generative Perspectives in Language Acquisition, John Benjamins, Amsterdam.

Hauser, M., N. Chomsky, and W. T. Fitch (2002) "The Language Faculty: What Is It, Who Has It, and How Did It Evolve?" Science 298, 1569-1579.

Herrnstein, R. and D. Loveland (1975) "Maximizing and matching on concurrent ratio schedules," Journal of the Experimental Analysis of Behavior 24, 107-116.

Hoekstra, T. and N. Hyams (1998) “Aspects of Root Infinitives,” Lingua 106, 81-112. 
Hyams, N. (2007) "Aspectual Effects on Interpretation in Early Grammar," Language Acquisition $14,231-268$.

Kroch, A. (2001) "Syntactic Change," in M. Baltin and C. Collins, eds., The Handbook of Contemporary Syntactic Theory, Basil Blackwell, Oxford.

Lasser, I. (2002) "The Roots of Root Infinitives: Remarks on Infinitival Main Clauses in Adult and Child Language," Linguistics 40, 767-796.

Legate, J. A. and C. D. Yang (2002) "Empirical Re-Assessment of Stimulus Poverty Arguments," The Linguistic Review 19, 151-162.

van der Lely, H. K. J. and J. Battell (2003) "Wh-Movement in Children with Grammatical SLI: A Test of the RDDR Hypothesis," Language 79, 153-181.

Leonard, L., U. Bertolini, M. Caselli, K. McGregor, and L. Sabbadini (1992) "Morphological Deficits in Children with Specific Language Impairment: The Status of Features in the Underlying Grammar," Language Acquisition 2, 115-179.

Macnamara, J. (1982) Names for Things: A Study of Human Learning, MIT Press, Cambridge, MA.

MacWhinney, B. (1995) The CHILDES Project: Tools for Analyzing Talk, Lawrence Erlbaum, Mahwah, NJ.

McDaniel, D. (1989) "Partial and Multiple wh-Movement," Natural Language and Linguistic Theory 7, 565-604

Oltra-Massuet, I. and K. Arregi (2005) "Stress-By-Structure in Spanish," Linguistic Inquiry 36, 43-84.

Phillips, C. (1995) "Syntax at Age 2: Cross-Linguistic Differences," in MIT Working Papers in Linguistics (MITWPL), 26, Cambridge, MA.

Pierce, A. (1992) Language Acquisition and Syntactic Theory: A Comparative Analysis of French and English, Kluwer, Dordrecht.

Pine, J., C. Rowland, E. Lieven, and A. Theakston (2005) "Testing the Agreement/Tense Omission Model: Why the Data on Children's Use of Non-Nominative 3psg Subjects Count Against the ATOM," Journal of Child Language 32, 269-289.

Pinker, S. (1984) Language Learnability and Language Development, Harvard University Press, Cambridge, MA.

Platzack, C. (1990) "A Grammar Without Functional Categories: A Syntactic Study of Early Swedish Child Language," Working Papers in Scandinavian Syntax 45, 13-34, University of Lund.

Pollock, J.-Y. (1989) "Verb Movement, Universal Grammar and the Structure of IP," Linguistic Inquiry 20, 261-305.

Radford, A. (1990) Syntactic Theory and the Acquisition of English Syntax, Basil Blackwell, Oxford.

Rasetti, L. (2003) Optional Categories in Early French Syntax: A Developmental Study of Root Infinitives and Null Arguments, Doctoral dissertation, Université de Genève.

Rice, M. and K. Wexler (1996) "Toward Tense as a Clinical Marker for Specific Language Impairment in English-Speaking Children," Journal of Speech and Hearing Research 39, 1239-1257.

Rice, M., K. Wexler, and S. Hershberger (1998) "Tense over Time: The Longitudinal Course of Tense Acquisition with Specific Language Impairments," Journal of Speech, Language, and Hearing Research 41, 1412-1431.

Rice, M., K. Wexler, J. Marquis, and S. Hershberger (2000) "Acquisition of Irregular Past Tense by Children with Specific Language Impairments," Journal of Speech, Language, and Hearing Research 43, 1126-1145.

Rizzi, L. (1994) "Some Notes on Linguistic Theory and Language Development: The Case of Root Infinitives," Language Acquisition 3, 371-393.

Rizzi, L. (2005) Grammatically Based Target Inconsistencies in Child Language, Manuscript, University of Siena, Italy.

Roeper, T. (2000) "Universal Bilingualism," Bilingualism: Language and Cognition 2, 169-185.

Sano, T. (1999) "Verbal Inflection in the Acquisition of Japanese," Linguistics and Interdisciplinary Research 3-B, 427-438. 
Sano, T. and N. Hyams (1994) "Agreement, Finiteness, and the Development of Null Arguments," Proceedings of NELS 24.

Schaeffer, J. and D. Ben Shalom (2004) "On Root Infinitives in Child Hebrew," Language Acquisition $12,83-96$.

Schütze, C. and K. Wexler (1996) "Subject Case Licensing and English Root Infinitives," in A. Stringfellow, D. Cahana-Amitay, E. Hughes, and A. Zukowski, eds., Proceedings of the 20th Boston University Conference on Language Development, 670-681.

Shibatani, M. (1977) "Grammatical Relations and Surface Cases," Language 53, 780-809.

Smith, C. (1991) The Parameter of Aspect, Kluwer, Boston.

Stromswold, K., and K. Zimmerman (1999) "Acquisition of Nein and Nicht and the VP-Internal Subject Stage in German," Language Acquisition 8, 101-127.

Thornton, R. (1990) Adventures in Long-Distance Moving: The Acquisition of Complex wh-Questions, Doctoral dissertation, University of Connecticut, Stoors, CT.

Torres, V. (1995) "The Acquisition of Inflection in Spanish and Catalan," in MIT Working Papers in Linguistics (MITWPL), 26, Cambridge, MA.

de Villiers, J. (2001) "Continuity and Modularity in Language Acquisition and Research," Annual Review of Language Acquisition 1, 1-64.

Weinberg, A. (1994) "Comments on Ken Wexler," in D. Lightfoot and N. Hornstein, eds., Verb Movement, Cambridge University Press, Cambridge.

Westergaard, M. (2006) "Triggering V2: The Amount of Input Needed for Parameter Setting in a Split-CP Model of Word Order," in A. Belletti, E. Bennati, C. Chesi, E. Di Domenico, I. Ferrari, eds. Language Acquisition and Development: Proceedings of GALA 2005, Cambridge Scholars Press.

Weverink, M. (1989) The Subject in Relation to Inflection in Child Language, M.A. thesis, University of Utrecht, Germany.

Wexler, K. (1994) "Optional Infinitives, Head Movement, and the Economy of Derivation in Child Language," in D. Lightfoot and N. Hornstein, eds., Verb Movement, Cambridge University Press, Cambridge.

Wexler, K. (1998) "Very Early Parameter Setting and the Unique Checking Constraint: A New Explanation of the Optional Infinitive Stage," Lingua 106, 23-79.

Whitman, J. (1994) "In Defense of the Strong Continuity Account of the Acquisition of Verb Second," in B. Lust, M. Suñer, J. Whitman, eds., Syntactic Theory and First Language Acquisition, Lawrence Erlbaum, Hillsdale, NJ.

Wijnen, F. (1997) "Temporal Reference and Eventivity in Root Infinitives," MIT Occasional Papers in Linguistics 12.

Wijnen, F. and G. Bol (1993) "The Escape from the Optional Infinitive Stage," in A. de Boer, J. de Jong, and R. Landeweerd, eds., Language and Cognition, Yearbook of the Research Group for Theoretical and Experimental Linguistics of the University of Groningen, Centre for Language and Cognition, Groningen.

Wijnen, F., M. Kempen, and S. Gillis (2001) "Bare Infinitives in Dutch Early Child Language: An Effect of Input?" Journal of Child Language 28, 629-660.

Yang, C. (1999) "A Selectionist Theory of Language Acquisition," Proceedings of the 37th Meeting of the Association for Computational Linguistics, East Stroudsburg, PA.

Yang, C. (2002) Knowledge and Learning in Natural Language, Oxford University Press, New York.

Yang, C. (2004) “Universal Grammar, Statistics, or Both,” Trends in Cognitive Sciences 8, 451-456.

Submitted 19 September 2005

Final version accepted 28 August 2006 